\title{
Türkiye'nin İç Anadolu Bölgesi'ndeki Bazı Su Ürünleri Kooperatiflerinin Yapısı ve Av Araçları ile Balıkçı Teknelerinin Teknik Özellikleri
}

\author{
Hasan DEMIR ${ }^{\circledR}$, Serap SAMSUN*(i) \\ Ordu Üniversitesi, Fatsa Deniz Bilimleri Fakültesi, Fatsa, Ordu, Türkiye \\ *Sorumlu Yazar: serapsamsun@hotmail.com
}

Araștırma Makalesi

Geliş 03 Şubat 2020; Kabul 16 Ağustos 2020; Basım 01 Eylül 2020.

Alıntılama: Demir, H., \& Samsun, S. (2020). Türkiye'nin İç Anadolu bölgesi’ndeki bazı su ürünleri kooperatiflerinin yapısı ve av araçları ile balıkçı teknelerinin teknik özellikleri. Acta Aquatica Turcica, 16(3), $344-352$. https://doi.org/10.22392/actaquatr.683741

\section{Özet}

Bu çalıșma, Mart 2018-Mart 2019 tarihleri arasında, İç Anadolu Bölgesi’nde bulunan Kayseri, Kırşehir, Nevşehir, Sivas ve Yozgat illerinde yürütülmüştür. Bu illerin sınırları içerisinde yer alan kooperatifler, kuruluş yılı, avlak sahaları, balıkçı sayısı, tekne sayısı, balıkçı teknelerinin özellikleri, kullanılan av araçlarının çeşitleri ve özellikleri, avlanan su ürünleri miktarı ve türlerine yönelik veriler anket çalışması ile elde edilmiştir. Bu veriler tam sayım yöntemi ile değerlendirilmiştir.

Çalışma sonucunda; İç Anadolu Bölgesinde araştırma yapılan illerde toplam 9 adet Su Ürünleri Kooperatifinin bulunduğu, bu kooperatiflere bağlı bulunan balıkçı sayısının 175, tekne sayısının ise 138 adet olduğu tespit edilmiştir. Su ürünleri avcılığında kullanılan sade ağların uzunluğunun $165920 \mathrm{~m}$, fanyalı ağların uzunluğunun $58400 \mathrm{~m}$, pinter ağlarının 3250 adet ve manyat ağlarının 85 adet olduğu belirlenmiştir. Bölgede incelenen teknelerin uzunlukları 3,5-7,5 m, genişlikleri 1,2-1,6 m, derinlikleri 0,4-1,4 m ve motor güçleri de 7-25 HP arasında değişmektedir.

Anahtar Kelimeler: Balıkçı tekneleri, İçsu balıkçıllı̆ı, Su ürünleri kooperatifi, İç Anadolu Bölgesi, Türkiye

The Structure of Some Fisheries Cooperatives and Technical Properties of Fishing Gears and Vessels in Internal Anatolia Region of Turkey

\section{Absract}

This study was conducted in Kayseri, Kırşehir, Nevşehir, Sivas and Yozgat provinces in Internal Anatolia Region, of Turkey between March 2018- March 2019. Data of cooperatives, years of foundation, fishing areas, fisherman number, number and properties of fishery vessels, types and specifications of fishing gears, fish species and landings were obtained through a survey study. in these provinces. These data have been determined by complete counts method.

As a result of the study, it was determined that there were 9 cooperatives, 175 fisherman and 138 vessels belonging to fisheries cooperatives. It was determined that total length of the gillnet $165920 \mathrm{~m}$, trammel net $58400 \mathrm{~m}$, number of fyke nets 3250 and seine nets as 85 . The size of fishing vessels were between 3.5 and $7.5 \mathrm{~m}$ in length, width 1.2-1.6 m, depth 0.4-1.4 m and engine power 7.-25 HP.

Keywords: Fishing vessels, Inland water fishing, Fisheries cooperative, Internal Anatolia Region, Turkey

\section{GİRİŞ}

Türkiye'de hızlı nüfus artışına paralel olarak ortaya çıkan enerji ihtiyacı ülkemizin zengin akarsularının kullanılması sonucunu beraberinde getirmiştir. Sayıları devamlı olarak artan hidroelektrik santralleri ve bunlarla beraber oluşan baraj gölleri ülkenin enerji ihtiyaçlarını karşıladıkları gibi su ürünleri bakımından da büyük bir potansiyel oluşturmuşlardır (Duman, 1998). İç Anadolu Bölgesi Su Ürünleri Kooperatiflerinin faaliyetlerinin yoğun bir şekilde gerçekleştirildiği Hirfanlı, Yamula, Bayramhacılı, Süreyyabey, Bahçelik ve Pınarbaşı barajları, hidroelektrik potansiyelinin yanında, balık üretimine katkı sağlayan önemli içsu kaynaklarıdır (Anonim, 2018a).

2017 y1lı Türkiye iç su ürünleri toplam üretimi 136.155 ton/yıl olup, bu üretimin 32.145 tonu avcılık yoluyla elde edilmiştir. İç Anadolu Bölgesi \% 21 (6626 ton) ile üretimde ikinci sırada yer almaktadır. Kayseri, Kırşehir, Nevşehir ve Yozgat illeri, toplam 3282 ton ile İç Anadolu Bölgesi üretiminin \% 50'sini sağlamıştır (TÜİK, 2018).

Yozgat ili Kızılırmak ve Yeşilırmak havzalarında yer almaktadır. Kızılırmak'ın kollarından olan Delice Irmağı ve Yeşilırmak'ın kollarından olan Çekerek Irmağı ilin en önemli su kaynaklarındandır. Balıkçılık faaliyetlerinin de yürütüldüğü Süreyyabey Barajı'ndan sulama ve enerji eldesi, Gelingüllü 
Barajı'ndan ise tarımsal sulamada yararlanılmaktadır. Süreyyabey Barajı yüzey alanı 4.133 hektar ve Gelingüllü Barajı yüzey alanı 2.320 hektardır (Anonim, 2013). Kırşehir ili, güney ve güneybatıda Kızılırmak, batı ve kuzeybatı Kılıçözü deresi, kuzey ve kuzeydoğuda Delice 1rmağı, doğuda Seyfe Gölü çöküntü alanı ile çevrilidir. Hirfanlı Baraj Gölü, Kaman ilçesine bağlı Hirfanlı Köyü yakınlarında elektrik üretimi ve tarımsal sulama sağlamaktadır. Türkiye’nin dördüncü en büyük barajı olan Hirfanlı Baraj Gölü'nün balıkçılık faaliyetleri için kullanılan 5. Bölgesinin yüzey alanı 6.000 hektar ve 6. Bölgesinin yüzey alanı ise 5.000 hektardır (Anonim, 2018b). Nevşehir ilinin başlıca akarsuyunu ise il topraklarından geçen Kızılırmak oluşturur. Nevşehir ili Avanos ilçesinde sınırları bulunan Göynük su ürünleri kooperatifi Bayramhacılı Barajı’nın avcılık yüzey alanı 460 hektar, Ürgüp ilçesi Mustafapaşa kasabası Damsa Barajı yüzey alanı 82 hektardır (Anonim, 2018c). Kayseri ilinin önemli akarsularının başında Kızılırmak gelmektedir. Kızılırmak Nehri'nin 128 kilometrelik bölümü Kayseri il sınırları içerisinde yer almaktadır. Kayseri ili su ürünleri kooperatifleri tarafından balıkçılık faaliyetlerinin gerçekleştirildiği Kocasinan ilçesinde bulunan Yamula Barajı'nın yüzey alanı 5.080 hektar, Kocasinan ilçesinin sınırlarında bulunan Bayramhacılı Barajı'nın alanı 1.480 hektar ve Pınarbaşı ilçesinde bulunan Bahçelik Barajı'nın yüzey alanı ise 588 hektardır (Anonim, 2018d).

Balıkçı kooperatifleri deniz balıkçılığı, iç su balıkçılığı ve yetiştiricilik sektöründe olmak üzere dünyanın hemen her tarafinda bulunmaktadır. Türkiye'de bu kooperatifler daha ziyade geleneksel balıkçı1ık ağırlıklı faaliyet göstermektedir (Karademir ve Arat, 2014). 2018 yılı Tarım ve Orman Bakanlığı tarımsal örgütlenme verilerine göre halen Türkiye'de, 30.763 ortağıyla, deniz ve iç sularda faaliyet gösteren 556 su ürünleri kooperatifi, 17 kooperatif bölge birliği, 1 kooperatif merkez birliği bulunmaktadır (Anonim, 2019).

$\mathrm{Bu}$ çalışmanın amacı, yukarıda belirtilen 4 il sınırları içerisinde kalan bölgedeki balıkçılık faaliyetlerinin belirlenmesi kapsamında; bölgedeki kooperatiflerin yapısı ile balıkçılıkta kullanılan av araçları ve balıkçı teknelerinin teknik özelliklerinin belirlenmesidir.

\section{MATERYAL ve YÖNTEM}

Araştırmada, İç Anadolu Bölgesi’nde bulunan, Kayseri, Kırşehir, Nevşehir ve Yozgat illeri sınırları içerisindeki 7 adet baraj gölünde balıkçılık faaliyetlerini yürüten 9 adet Su Ürünleri Kooperatifi incelenmiştir. Bu amaçla, su ürünleri kooperatif başkanları ve üyeleri ile birebir görüşülerek anket formları doldurulmuştur. Anket formlarında; su ürünleri kooperatiflerindeki avcılık yapan balıkçıların sayısı, su ürünleri avcılığında kullanılan balıkçı teknelerinin sayısı ve özellikleri (motor markası, motor gücü, tekne eni, boyu, derinliği, tonaj1), su ürünleri avcılığında kullanılan av araç ve gereçlerinin çeşitleri ve özellikleri (göz genişliği, uzunlukları), avlanan su ürünleri türleri ve miktarının belirlenmesine yönelik sorulara yer verilmiştir. Ayrıca araştırma kapsamındaki illerin İl Tarım ve Orman Müdürlükleri'nden de kooperatiflere ve balıkçılara ait istatistiki veriler alınmıştır.

\section{BULGULAR}

Araştırmada İç Anadolu Bölgesi'nde yer alan Kayseri, Kırşehir, Nevşehir ve Yozgat illeri sınırları içerisinde faaliyet gösteren 9 adet su ürünleri kooperatifi incelenmiştir. Kooperatiflerin isim ve kuruluş yılları Tablo 1'de, çalışma bölgesindeki kooperatif sayılarının illere göre dağılımı ise Şekil 1'de verilmiş̧ir.

Tablo 1. İncelenen Su Ürünleri Kooperatifleri ve kuruluş yılları

\begin{tabular}{llc}
\hline \hline Baraj Gölleri & Su Ürünleri Koopertif Adı & Kuruluş Yılı \\
\hline Gelingüllü Baraj Gölü & Esenli Su Ürünleri Kooperatifi & 1994 \\
\hline \multirow{2}{*}{ Bayramhacılı Baraj Gölü } & Göynük Su Ürünleri Kooperatifi & 1996 \\
\cline { 2 - 3 } & Bayramhacılı Su Ürünleri Kooperatifi & 2012 \\
\hline \multirow{2}{*}{ Hirfanlı Baraj Gölü } & Savcılı Su Ürünleri Kooperatifi & 2006 \\
\cline { 2 - 3 } & Toklümen Su Ürünleri Kooperatifi & 2017 \\
\hline Damsa Baraj Gölü & Mustafapaşa Su Ürünleri Kooperatifi & 2000 \\
\hline Bahçelik Baraj Gölü & Bahçelik (Pnnarbaşı) Su Ürünleri Kooperatifi & 2009 \\
\hline Yamula Baraj Gölü & Yamula Su Ürünleri Kooperatifi & 2010 \\
\hline Süreyyabey Baraj Gölü & Çekerek Su Ürünleri Kooperatifi & 2014 \\
\hline \hline
\end{tabular}




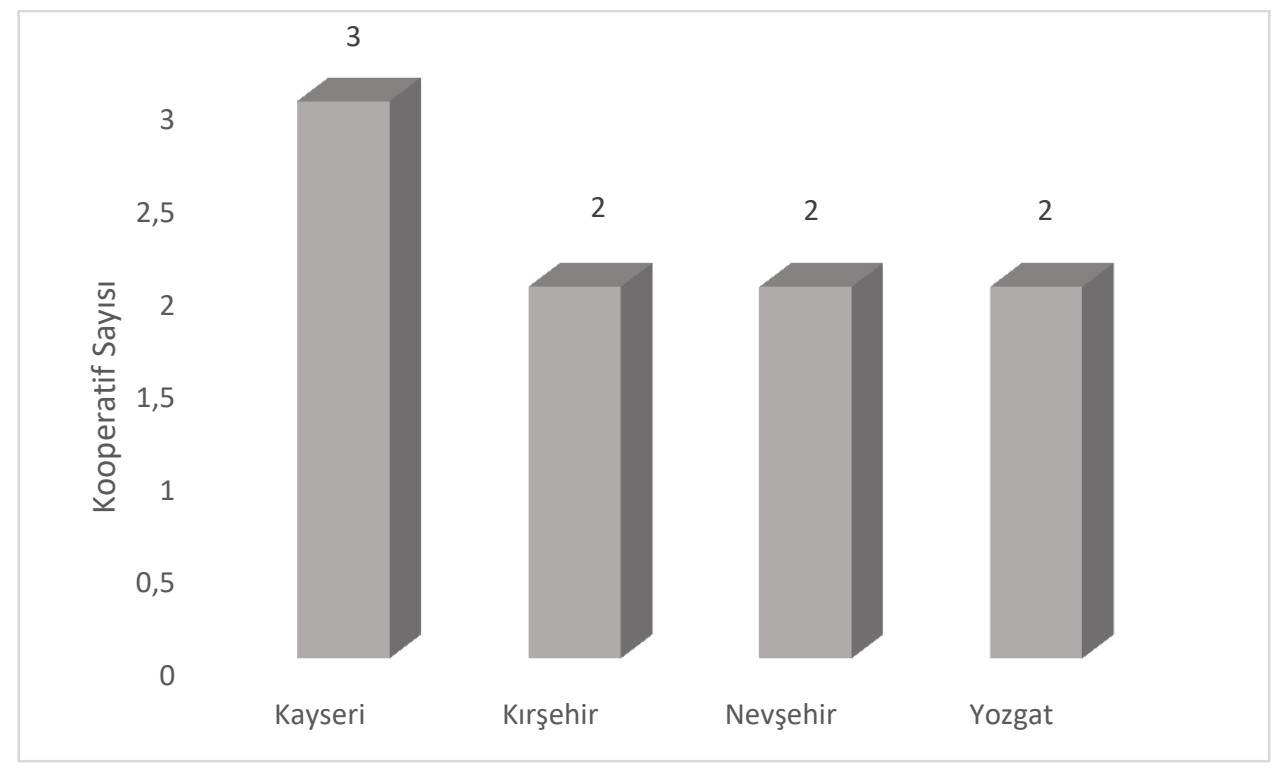

Şekil 1. Su Ürünleri Kooperatif sayılarının illere göre dağılımı

Araştırmada incelenen su ürünleri kooperatiflerine kayıtlı toplam balıkçı sayısı 175, tekne sayısı ise 138 olarak belirlenmiştir. Esenli Kasabası ve Çevre Köyleri Su Ürünleri Kooperatifi 40 kişi ile en fazla üye sayısına sahip iken Yamula Su ürünleri Kooperatifi 38 ile en fazla balıkçı teknesine sahip kooperatif olarak belirlenmiştir (Tablo 2).

Tablo 2. Balıkçı ve tekne sayılarının kooperatiflere göre dağılımı

\begin{tabular}{|c|c|c|c|c|c|c|c|}
\hline \multirow[b]{2}{*}{ İller } & \multirow[b]{2}{*}{ Su kaynağı } & \multirow{2}{*}{$\begin{array}{c}\text { Parsel } \\
\text { Alanı } \\
\text { (Ha) }\end{array}$} & \multirow[b]{2}{*}{ Kooperatifin Adı } & \multicolumn{2}{|c|}{ Balıkçı Sayısı } & \multicolumn{2}{|c|}{ Tekne Sayısı } \\
\hline & & & & Sayı & $\%$ & Sayı & $\%$ \\
\hline \multirow{3}{*}{ Kayseri } & Yamula Barajı & 5080 & Yamula Su ürünleri Kooperatifi & 20 & 11,4 & 38 & 27,5 \\
\hline & $\begin{array}{l}\text { Bayramhacılı } \\
\text { Baraj1 2. Bölge }\end{array}$ & 1480 & $\begin{array}{c}\text { Bayramhac1lı Su Ürünleri } \\
\text { Kooperatifi }\end{array}$ & 7 & 4 & 6 & 4,3 \\
\hline & Bahçelik Barajı & 588 & $\begin{array}{c}\text { Bahçelik (P1narbaşı) Su Ürünleri } \\
\text { Kooperatifi }\end{array}$ & 7 & 4 & 2 & 1,4 \\
\hline \multirow{2}{*}{ Kırşehir } & $\begin{array}{c}\text { Hirfanlı Barajı } 5 . \\
\text { Bölge }\end{array}$ & 6000 & $\begin{array}{l}\text { Toklümen Su Ürünleri } \\
\text { Kooperatifi }\end{array}$ & 33 & 18,9 & 30 & 21,7 \\
\hline & $\begin{array}{c}\text { Hirfanlı Baraj1 } 6 . \\
\text { Bölge }\end{array}$ & 5000 & Savc1lı Su Ürünleri Kooperatifi & 18 & 10,3 & 20 & 14,5 \\
\hline \multirow{2}{*}{ Nevşehir } & $\begin{array}{c}\text { Bayramhacıl1 } \\
\text { Baraj1 1. Bölge }\end{array}$ & 460 & Göynük Su Ürünleri Kooperatifi & 17 & 9,7 & 2 & 1,4 \\
\hline & Damsa Baraj1 & 82 & $\begin{array}{l}\text { Mustafapaşa Su Ürünleri } \\
\text { Kooperatifi }\end{array}$ & 15 & 8,6 & 1 & 0,7 \\
\hline \multirow{2}{*}{ Yozgat } & Gelingüllü Barajı & 2320 & $\begin{array}{c}\text { Esenli Kasabası ve Çevre Köyleri } \\
\text { Su Ürünleri Kooperatifi }\end{array}$ & 40 & 22,9 & 23 & 17,7 \\
\hline & $\begin{array}{l}\text { Süreyyabey } \\
\text { Baraj1 }\end{array}$ & 4133 & Çekerek Su Ürünleri Kooperatifi & 18 & 10,3 & 16 & 11,6 \\
\hline Toplam & & 25143 & & 175 & 100 & 138 & 100 \\
\hline
\end{tabular}

Araştırma kapsamında kooperatiflerde su ürünleri avcılığında kullanılan teknelerin boyu 3,5-7,5 m, eni 1,2-1,6 m ve derinliği $0,4-1,4 \mathrm{~m}$ arasında değişmektedir. Tamamı fiberglass malzemeden yapılmış olan teknelerin 5 adedi motorsuz geri kalan 133 adedi ise motorludur (Tablo 3). Teknelerin tamamında baş kısmının balta baş, kıç kısmının ise 6 metre ve üzerindekilerde ördek kıç ve karpuz oturtma şeklinde, 6 metreden küçük teknelerde ayna kıç biçiminde olduğu belirlenmiştir 
Tablo 3. Su Ürünleri Kooperatiflerinin kullandığı teknelere ait bilgiler

\begin{tabular}{|c|c|c|c|c|c|c|c|c|c|}
\hline \multirow{2}{*}{ Kooperatifin Adı } & \multirow{2}{*}{$\begin{array}{l}\text { Tekne } \\
\text { Sayısı }\end{array}$} & \multirow{2}{*}{$\begin{array}{l}\text { Boy } \\
\text { (m) }\end{array}$} & \multirow{2}{*}{$\begin{array}{l}\text { En } \\
\text { (m) }\end{array}$} & \multirow{2}{*}{$\begin{array}{l}\text { Derinlik } \\
\text { (m) }\end{array}$} & \multirow{2}{*}{$\begin{array}{r}\text { Tonaj } \\
\text { (ton) }\end{array}$} & \multicolumn{3}{|c|}{ Motor Tipi } & \multirow{2}{*}{$\begin{array}{c}\text { Yapı } \\
\text { Malzemes }\end{array}$} \\
\hline & & & & & & Lombardini & Mercury & Motorsuz & \\
\hline Yamula Su ürünleri Kooperatifi & 38 & $7,3-7,5$ & 1,5 & 0,8 & 1,5 & 38 & - & - & Fiberglass \\
\hline Bayramhacılı Su Ürünleri Kooperatifi & 6 & $4,5-6,5$ & $1,2-1,5$ & $0,5-0,7$ & $0,3-1,5$ & 4 & - & 2 & Fiberglass \\
\hline $\begin{array}{l}\text { Bahçelik (Pınarbaşı) Su Ürünleri } \\
\text { Kooperatifi }\end{array}$ & 2 & 3,5 & 1,2 & 0,5 & 0,15 & - & - & 2 & Fiberglass \\
\hline Toklümen Su Ürünleri Kooperatifi & 30 & $7,3-7,5$ & 1,6 & $0,8-1$ & $1,5-2$ & 30 & - & - & Fiberglass \\
\hline Savcılı Su Ürünleri Kooperatifi & 20 & $7,3-7,5$ & 1,6 & $0,8-0,9$ & $1,5-2$ & 20 & - & - & Fiberglass \\
\hline Göynük Su Ürünleri Kooperatifi & 2 & $7,3-7,5$ & $1,5-1,6$ & 0,7 & 1 & 2 & - & - & Fiberglass \\
\hline Mustafapaşa Su Ürünleri Kooperatifi & 1 & 3,5 & 1,3 & 0,4 & 0,1 & - & - & 1 & Fiberglass \\
\hline Esenli Su ürünleri Kooperatifi & 23 & $6-7,3$ & $1,5-1,6$ & $0,7-1,4$ & $1-3$ & 23 & - & - & Fiberglass \\
\hline Çekerek Su Ürünleri Kooperatifi & 16 & $4,5-7,3$ & $1,4-1,6$ & $0,6-1,3$ & $0,8-3,5$ & 15 & 1 & - & Fiberglass \\
\hline
\end{tabular}


Araştırmada incelenen kooperatifler tarafından su ürünleri avcılığında sade ve fanyalı ağlar, manyat ve kerevit sepetleri kullanılmaktadır (Tablo 4). Su ürünleri kooperatifleri tarafından kullanılan fanyalı ve sade ağların toplam uzunluğu $224320 \mathrm{~m}$ olup, fanyalı ağların uzunluğu $58400 \mathrm{~m}$, sade ağların uzunluğu ise 165920 m'dir (Tablo 5). Kerevit avcılığında kullanılan pinterlerin göz açıklığ 15-25 $\mathrm{mm}$, boyları ise $75-150 \mathrm{~cm}$ arasında değişmektedir. Özellikle gümüş balığı avcılığında kullanılan manyat ağlarını torba göz açıklı̆̆ 4-10 mm, kanat uzunlukları ise 50-220 m arasında değişmektedir.

Tablo 4. İllere göre kullanılan av araçları ve sayıları

\begin{tabular}{|c|c|c|c|c|c|c|c|c|c|}
\hline \multirow[t]{2}{*}{ İller } & \multirow[t]{2}{*}{ Su Kaynağı } & \multicolumn{2}{|c|}{$\begin{array}{c}\text { Fanyalı A } \breve{g} \\
(1 \text { Tk: } 100 \text { m) }\end{array}$} & \multicolumn{2}{|c|}{$\begin{array}{c}\text { Sade Ă } \\
\text { (1Tk: } 100 \text { m) }\end{array}$} & \multicolumn{2}{|c|}{$\begin{array}{c}\begin{array}{c}\text { Manyat Ăğ } \\
\text { (Adet) }\end{array} \\
\end{array}$} & \multicolumn{2}{|c|}{$\begin{array}{c}\begin{array}{c}\text { Kerevit Sepeti } \\
\text { (Adet) }\end{array} \\
\end{array}$} \\
\hline & & Takım & $\%$ & Takım & $\%$ & Adet & $\%$ & Adet & $\%$ \\
\hline \multirow{3}{*}{ Kayseri } & Yamula Barajı & - & - & 195 & 12 & 20 & 23,5 & - & - \\
\hline & $\begin{array}{l}\text { Bayramhac1lı Baraj1 } \\
\text { 2. Bölge }\end{array}$ & - & - & 30 & 1.9 & - & - & - & - \\
\hline & Bahçelik Barajı & 4 & 1.0 & 4 & 0.2 & - & - & - & - \\
\hline \multirow{2}{*}{ Kırş̧ehir } & $\begin{array}{l}\text { Hirfanl1 Baraj1 } 5 . \\
\text { Bölge }\end{array}$ & 234 & 56,9 & 966 & 59,6 & 30 & 35,3 & 1500 & 46,2 \\
\hline & $\begin{array}{l}\text { Hirfanlı Baraj1 } 6 . \\
\text { Bölge }\end{array}$ & - & - & 360 & 22,2 & 18 & 21,2 & 1000 & 30,8 \\
\hline \multirow[t]{2}{*}{ Nevşehir } & $\begin{array}{l}\text { Bayramhac11ı Barajı } \\
\text { 1. Bölge }\end{array}$ & - & - & 20 & 1,2 & 2 & 2,4 & - & - \\
\hline & Damsa Barajı & - & - & $6 *$ & 0,4 & - & - & - & - \\
\hline \multirow[t]{2}{*}{ Yozgat } & Gelingüllü Barajı & $100 * *$ & 24,3 & $30 * *$ & 1,9 & 10 & 11,8 & 500 & 15,4 \\
\hline & Süreyyabey Baraj1 & $73 * *$ & 17,8 & $10 * *$ & 0,6 & 5 & 5,9 & 250 & 7,6 \\
\hline Toplam & & 411 & 100 & 1621 & 100 & 85 & 100 & 3250 & 100 \\
\hline
\end{tabular}

*1 Tk: $70 \mathrm{~m}$

** $1 \mathrm{Tk}: 200 \mathrm{~m}$

Tablo 5. Kooperatifler tarafindan kullanılan sade ve fanyalı ağlara ait bilgiler

\begin{tabular}{lcccc}
\hline \hline Kooperatifin Adı & $\begin{array}{c}\text { Toplam Ăg } \\
\text { Uzunluğu } \\
(\mathbf{m})\end{array}$ & $\begin{array}{c}\text { Sade Ağların Göz } \\
\text { Açıklıları (mm) }\end{array}$ & \multicolumn{2}{c}{$\begin{array}{c}\text { Fanyalı Ağların Göz Açıklıkları } \\
\text { (mm) }\end{array}$} \\
\cline { 5 - 5 } & 19500 & $60-70-80-90-100$ & Fanya & Tor \\
\hline Yamula Su Ürünleri Kooperatifi & 3000 & $70-80-90-120$ & - & - \\
Bayramhacılı Su Ürünleri & 800 & $60-70-80$ & - & - \\
Kooperatifi & 120000 & $65-70-80-90-100-110-120$ & $200-220-240$ & $45-50-65-75$ \\
Bahçelik Su Ürünleri Kooperatifi & 36000 & $55-60-65-70-75-80-90$ & - & - \\
Toklümen Su Ürünleri Kooperatifi & 2000 & $45-50-60-70-90-120-140$ & - & - \\
Savcılı Su Ürünleri Kooperatifi & 420 & $45-55-75-80-85-90$ & - & - \\
Göynük Su Ürünleri Kooperatifi & & $60-65-70-75-80-85$ & $120-140-160-180$ & $36-38-40-42-45-55$ \\
Mustafapaşa Su Ürünleri & 26000 & $45-55-65-70-80$ & $120-140-160-180$ & $36-38-40-42-45-55$ \\
Kooperatifi & 16600 & & & \\
Esenli Su Ürünleri Kooperatifi & & & & - \\
Çekerek Su Ürünleri Kooperatifi & &
\end{tabular}

Çalışma bölgesindeki su ürünleri kooperatiflerine üye balıkçılar tarafından yıllık avlanan su ürünleri miktarı yaklaşık 2295 ton/yıl'dır (Tablo 6). 
Tablo 6. İllere göre Kooperatifler tarafindan avlanan su ürünleri miktarları

\begin{tabular}{|c|c|c|c|}
\hline \multirow{2}{*}{ İller } & \multirow{2}{*}{ Kooperatifin Adı } & \multicolumn{2}{|c|}{ Yıllık Av Miktarı (ton/yıl) } \\
\hline & & Miktar & $\%$ \\
\hline \multirow{3}{*}{ Kayseri } & Yamula Su Ürünleri Kooperatifi & 440 & 19,2 \\
\hline & Bayramhacılı Su Ürünleri Kooperatifi & 16 & 0,7 \\
\hline & Bahçelik Su Ürünleri Kooperatifi & 8,8 & 0,4 \\
\hline \multirow[b]{2}{*}{ Kırşehir } & Toklümen Su Ürünleri Kooperatifi & 478 & 20,8 \\
\hline & Savc1lı Su Ürünleri Kooperatifi & 567 & 24,7 \\
\hline \multirow{2}{*}{ Nevşehir } & Göynük Su Ürünleri Kooperatifi & 16 & 0,7 \\
\hline & Mustafapaşa Su Ürünleri Kooperatifi & 4 & 0,2 \\
\hline \multirow{2}{*}{ Yozgat } & Esenli Su Ürünleri Kooperatifi & 315 & 13,7 \\
\hline & Çekerek Su Ürünleri Kooperatifi & 450 & 19,6 \\
\hline Toplam & & 2294,8 & 100 \\
\hline
\end{tabular}

Araştırma bölgesindeki su ürünleri kooperatifleri tarafindan avlanan balık türleri Tablo 7'de verilmiştir. Sazan balığı, Siraz balığı, Tatlı su Kefali ve Gümüş balığı avcılı̆̆ tüm illerde yapılmakla birlikte, Siraz balığı, Sudak balığı ve Tatlı su kefali bölgede en çok avcılığı yapılan türler olarak belirlenmiştir.

Tablo 7. Su Ürünleri Kooperatifleri tarafından avcıllı̆ı yapılan türler

\begin{tabular}{|c|c|c|c|c|}
\hline \multirow{2}{*}{ Avcılığı Yapılan Türler } & \multicolumn{4}{|c|}{ İller } \\
\hline & Kayseri & Kırssehir & Nevssehir & Yozgat \\
\hline Gümüş Balığı (Atherina boyeri) & $\sqrt{ }$ & $\sqrt{1}$ & $\sqrt{ }$ & $\sqrt{3}$ \\
\hline Kadife Balığ 1 (Tinca tinca) & - & $\sqrt{ }$ & $\sqrt{ }$ & - \\
\hline Sazan Balığı (Cyprinus carpio) & $\sqrt{ }$ & $\sqrt{ }$ & $\sqrt{ }$ & $\sqrt{ }$ \\
\hline Siraz Balığı (Capoeta pestai) & $\sqrt{ }$ & $\sqrt{ }$ & $\sqrt{ }$ & $\sqrt{ }$ \\
\hline Sudak Balı̆̆ı (Sander lucioperca) & $\sqrt{ }$ & $\sqrt{ }$ & - & $\sqrt{ }$ \\
\hline Tatlı Su Kefali (Squalius cephalus) & $\sqrt{ }$ & $\sqrt{ }$ & $\sqrt{ }$ & $\sqrt{ }$ \\
\hline Tatl1 Su Kereviti (Astacus leptodactylus) & - & $\sqrt{ }$ & - & - \\
\hline Turna Balığı (Esox lucius) & $\sqrt{ }$ & - & - & - \\
\hline Yayın Balığı (Silurus glanis) & $\sqrt{ }$ & $\sqrt{ }$ & - & - \\
\hline
\end{tabular}

Kooperatifler tarafindan avlanan su ürünlerinin fiyatları 0,8-15 TL arasında değişmektedir (Tablo 8). Araştırma bölgesindeki illerde avlanan su ürünleri türleri ihracatçı firmaya ve bölgede bulunan su ürünleri satış yerlerine pazarlanmaktadır.

Tablo 8. Kooperatifler tarafindan avlanan balıkların belirlenen fiyatlandırmaları

\begin{tabular}{|c|c|c|c|c|}
\hline \multirow{2}{*}{ Su Ürünleri Türleri } & \multicolumn{4}{|c|}{ Fiyatlandırma (TL) } \\
\hline & Kayseri & Kırşehir & Nevşehir & Yozgat \\
\hline Gümüş Balığ1 & 1 & $1,5-2$ & 1 & 1 \\
\hline Kadife Balığ1 & - & 2 & $3,5-5$ & - \\
\hline Sazan Balığı & $2-4$ & 5 & $4-5$ & $3-4$ \\
\hline Siraz Balığı & 0,8 & 2 & 2 & 2 \\
\hline Sudak Balığı & 6 & $5-10$ & - & $8-10$ \\
\hline Tatl1 Su Kefali & 1 & 2 & 3 & 2 \\
\hline Tatl1 Su Kereviti & - & $5-15$ & - & - \\
\hline Turna Balığg1 & 5 & - & - & - \\
\hline Yayın Balığı & $7-10$ & $10-15$ & - & - \\
\hline
\end{tabular}

Kırşehir ve Nevşehir illerinde su ürünleri av yasak dönemleri (15 Mart-15 Haziran), Kayseri ve Yozgat illerinde av yasak dönemleri (1 Nisan- 1 Temmuz) dışında hava şartlarının uygun olduğu günlerde avcılığın yapıldığı belirlenmiştir. Yıl boyu avcılığı serbest olan Gümüş balığının, su sıcaklığının artması ile sığlıklara gelmesi nedeniyle, en uygun avcılık zamanının Nisan ayı başlangıcından 40-50 gün içerisinde olduğu belirtilmiştir. 


\section{TARTIȘMA ve SONUC}

Araştırmada, İç Anadolu Bölgesi'nde bulunan Kayseri, Kırşehir, Nevşehir ve Yozgat illeri sınırları içerisinde yer alan 10 adet su ürünleri kooperatifi ve bu kooperatiflere ait balıçıllk faaliyetleri incelenmiştir.

Doğu ve Güneydoğu Anadolu Bölgelerinde incelenen 472 adet teknenin boylarının 4-12 m ve motor güçlerinin 4-11 HP ile $100 \mathrm{HP}$ arasında değiştiği, teknelerin 400 adedinin sac, 60 adedinin ağaç ve 12 adedinin fiberglas malzemeden olduğu tespit edilmiştir (Ural ve Canpolat, 2009). Yeni Karpuzlu Baraj Gölü'ndeki teknelerin boyları 4-7 m arasında, motor güçleri 4-15 HP arasında olup teknelerin \% 18,19'u motorsuzdur (Uzmanoğlu ve Soylu, 2012). Keban Baraj Gölü'nde 217 adet motorlu teknenin faal şekilde balık avcılığı yaptığı, boyları 5-8 m arasında değişen bu teknelerin 1,5-4 mm kalınlığında sac materyalden yapıldığı, motor güçlerinin 9-28 HP arasında, tonajlarının ise 1-3 ton değiştiği belirtilmiştir. Ayrıca genelde kamaraları bulunan bu balıkçı teknelerinde ağların atılıp çekilmesinde kullanılan makara, vinç gibi herhangi bir mekanik donanıma rastlanmadığı ifade edilmiştir (Celayir vd., 2006). İç Anadolu Bölgesinin doğu kesimini kapsayan bu çalışmada, su ürünleri kooperatiflerine kayitlı 138 tekne incelenmiş olup, teknelerin boyu 3,5-7,5 m, eni 1,2-1,6 m, derinliği 0,4-1,4 m, tonajları 0,1-3,5 ton ve motor güçleri ise 7-25 HP arasında değişmektedir. Tamamı fiberglass malzemeden yapılmış olan teknelerin 5 adedi motorsuz geri kalan 133 adedi ise motorludur. Teknelerin tamamında baş kısmının balta baş, kıç kısmının ise 6 metre ve üzerindekilerde ördek kıç ve karpuz oturtma şeklinde, 6 metreden küçük teknelerde ayna kıç biçiminde olduğu belirlenmiştir. Fiberglass malzemeden yapılmış teknelerin, daha dayanıklı olması, az bakım gerektirmesi ve hafif yapıda olmasından dolayı tercih edildiği tespit edilmiştir. Mevcut çalışma ve daha önceki çalışmalarda, avc1lıkta kullanılan teknelerin büyüklükleri çoğunlukla birbirine yakın olup bunun nedeni, kullanılan avcılık yöntemleri ve avlanılan balık türlerinin benzer olması olabilir.

Elazı ̆̆ ilinde kullanılan teknelerde motor markası Wiskonsin ve Yomaha olan tekneler benzinle, motor markası Pancar, Lombardini ve Onan olanlar ise mazotla çalıştırılmaktadır. Teknelerin bir günlük avcılık için, balıkçıların ifadesi ile, yarım yol ilerlendiğinde 1 litre, tam yol ilerlendiğinde ise 2 It mazot veya benzin harcadığı belirtilmiştir (Orsay ve Duman, 2005). Doğu ve Güneydoğu Bölgesindeki illerde su ürünleri avcıllğında kullanılan balıkçı teknelerinde Pancar, Lombardini, Süperstar, Jonhson, Köhler, Perkins, Onan, Wiskose, Tames, Ford vb. tekne motor markalarının kullanıldığı, en yaygın kullanılan markaların ise pancar (225) ve lombardini (160) marka olduğu belirlenmiştir (Ural ve Canpolat, 2009). Bu çalışmada ise kooperatiflerde kullanılan 133 adet motorlu teknenin 132 adedinin motor markasının Lombardini, 1 adedinin ise Mercury motorları olduğu belirlenmiştir.

Doğu ve Güneydoğu Bölgesi'nde su ürünleri avc1lığında, fanyalı ağlar (tor göz genişliği 15-140 $\mathrm{mm}$ ve fanya göz genişliği 100-250 mm arasında), galsama ağları (göz genişliği 18-140 mm arasında), pinter (ağ boyu $70 \mathrm{~cm}$ ve göz genişliği 16-18 mm arasında) ve manyat (torba göz genişliği $14-18 \mathrm{~mm}$ ve kanat uzunluğu 100-700 m arasında) kullanılmaktadır. Avlanma şekli ise, fanyalı ve sade ağların suya bırakılıp belli bir süre bekletilmesi ve tekrar toplanması, kıyı sürükleme aletlerinin (manyat) ise suya bırakıldıktan sonra kıyıya çekilmesi şeklinde gerçekleşmektedir (Ural ve Canpolat, 2009). Duman ve Karadağ, (2017), Keban Baraj Gölü Kemaliye Bölgesinde inceledikleri toplam 14000 m uzunluğunda sade ağın 12200 m'sinin monofilament sade ağlar, 1800 m'sinin de multifilament sade ağlardan oluştuğunu belirtmişlerdir. Monofilament ağların göz genişliği 38-110 mm arasında değişmekte olup en çok tercih edilen göz genişliği $45 \mathrm{~mm}$ 'dir. Aynı çalışmada, fanya göz genişliği $170-210 \mathrm{~mm}$ arasında, tor göz genişliği ise $38-65 \mathrm{~mm}$ arasında olan toplam $900 \mathrm{~m}$ uzunluğunda fanyalı ă ve kerevit avcılığında kullanılan, $17 \mathrm{~mm}$ ağ gözü genişliğine sahip toplam 1500 adet kerevit pinteri tespit edilmiştir. Celayir vd. (2006), Keban Baraj gölünde faaliyet gösteren su ürünleri kooperatiflerinde kullanılan çoğunluğu monofilament ve fanyasız yapıda olan $519000 \mathrm{~m}$ uzunluğunda uzatma ağ1 ve 40000 adet kerevit pinteri tespit etmişlerdir. Monofilament yapıda olan uzatma ağlarının ağ göz açıklıklarının 22-125 mm, multifilament yapıda olan uzatma ağlarının ağ göz açıklıklarının ise $28-180 \mathrm{~mm}$ olduğunu ve monofilament yapıdaki ağların avlama etkinliklerinin daha fazla olmasından dolayı balıkçıların bu tip ağlara yöneldiklerini belirtmişlerdir. Aynı çalışmada, kerevit avcılı̆̆ında kullanılan pinterlerin ise tek girişli, çift venterli 5 çemberli ve germeli olup ağ göz açıklıklarının 13-18 mm olduğu bildirilmiştir. Bu çalışmada, kooperatif üyeleri tarafından kullanılan fanyalı ve sade ağların toplam uzunluğu $224320 \mathrm{~m}$ olup, fanyalı ağların uzunluğu $58400 \mathrm{~m}$, sade ağların uzunluğu ise $165920 \mathrm{~m}$ olarak belirlenmiştir. Kerevit avcılığında kullanılan pinterlerin göz 
açıklığı 15-25 mm, boyları ise 75-150 cm arasında değişmektedir. Özellikle gümüş balığı avcılığında kullanılan manyat ağlarının torba göz açıklığı 4-10 mm, kanat uzunlukları ise 50-220 m arasında değişmektedir. Uzatma ağları tekli veya ağlar birbirine bağlanarak ikili gruplar halinde, bir gün öncesinden suya bırakılıp ertesi gün ağın toplanması şeklinde dönek yöntemi ile avcılıkta kullanılmaktadır. Manyat ağları, kanatların bir ucunun kıyıya sabitlenmesi ve tekneyle açılarak suda taranacak bölgenin ağ ile çevrildikten sonra ikinci kanadın ucundaki halatında kıyıya alınması şeklinde kullanılmaktadır. Tuzakların kullanımı ise suya bırakılan kerevit pinterleri birkaç gün sonra kontrol edilerek, yakalanan kerevitlerin alınması şeklindedir. İç sularda yapılan su ürünleri avcıllı̆ında çoğunlukla sade uzatma ağlarının kullanıldığı göze çarpmaktadır. Yapısal olarak çok büyük farklılıklar olmamakla birlikte, avlanılan suyun derinliği ve av miktarı açısından verimliliğine bağlı olarak, av araçlarının miktar ve büyüklükleri değişiklik göstermektedir.

Doğu ve Güneydoğu Bölgelerindeki su ürünleri kooperatiflerine üye balıkçılar tarafından toplam 530146 ha'lık bir alanda yıllık avlanan su ürünleri miktarı 6355 ton /yıl'dır. Van ili \% 70,03'lük oranla üretimde birinci sırada yer almaktadır (Ural ve Canpolat, 2009). Adıyaman ilinin 2013 yılı su ürünleri üretiminin 643 ton olduğu, bunun 172 ton'unun Siraz balığı, 164 ton'unun Bizir balığı ve156,5 ton'unun ise Sazan balığından oluştuğu belirtilmiştir. Ayrıca avlanan balık türlerinin 1,50-8,00 TL arasında değişen fiyatlarda satıldığı ifade edilmiştir (Bayhan vd., 2014). Mevcut çalışmada, İç Anadolu Bölgesi'nde çalışma yapılan illerdeki avlanan tatlısu üretiminin 2016-2017 av sezonunda sırasıyla, Kırşehir'de 1045 ton, Yozgat'ta 765 ton, Kayseri'de 464,8 ton ve Nevşehir'de 20 ton şeklinde olduğu tespit edilmiştir. Tüm illerde avlanan balıkların 2017-2018 yılı ortalama perakende satış fiyatları balığın türüne, avlanma miktarına, avcılık zamanına ve büyüklüğüne göre $0,80-15 \mathrm{TL} / \mathrm{kg}$ arasında değiştiği belirlenmiştir. Avlanan balık miktarlarındaki farklılıkların en önemli nedenlerinin başında avlak sahasının büyüklüğ̈̈ gelmektedir. Buna ilaveten balıkçı sayıları ve kullanılan av araçlarının miktarı da üretimi etkilemektedir.

İç Anadolu Bölgesi Su Ürünleri Kooperatifleri tarafından avlanan balıklar sadece iç pazarlara değil aynı zamanda yurtdışı ülkelerine de ihraç edilmektedir. Özellikle gümüş balığı, ülkemiz iç sularında yaygın olarak avlanmakta ve bazı Avrupa Birliği ülkelerine önemli miktarlarda ihraç edilmektedir. Diğer balık türlerinin avcılığının yasak olduğu dönemlerde, gümüş balığı balıkçılara alternatif gelir kaynağı olmaktadır.

Karaya çıkarılan av, kabzımallar ve komisyoncular tarafından karaya çıkış noktalarından alınarak pazara sunulmaktadır. Su ürünleri avcılığında en büyük sorunlarından biri de ürünlerin uygun şartlarda ve fiyatlarda pazarlanamamasıdır (Canpolat vd., 2015). Balıkçılar avladığı balıkları taze veya canlı olarak su ürünleri işleme tesislerine, ihracatçı firmalarına, balık satış yerlerine, seyyar satıcılara veya bölge halkına pazarlamaktadır. Ancak bazı balıkçılar ekonomik sıkıntılar nedeniyle komisyoncularla yıllık olarak satış sözleşmesi imzalamakta ve bu durum balıkçının avladığı ürünü daha düşük fiyata satmasına neden olmaktadır. Ayrıca, su ürünleri soğuk depolama tesislerinin bulunmayışından dolayı, avcılığın yoğun olarak yapıldığı dönemde, balıkçılar su ürünlerini muhafaza imkanları bulamayarak ürünlerini ucuza pazarlamak zorunda kalmaktadır.

İç sularda baraj göllerinin çevresinde bulunan yerleşim yerlerinde yaşayan yöre halkına gerek istihdam imkanı gerekse ek ekonomik katkı sağlayan balıkçılık faaliyetlerinin ve balık populasyonlarının sürdürülebilirliği açısından yapılacak uygulamalar ve alınacak önlemler büyük önem kazanmaktadır. Özellikle avlak sahalarından daha verimli bir şekilde faydalanmak için, yasak ve sınırlamaların uygulanırlığının, bölge halkı ve balıkçılarla işbirliği içerisinde gerçekleştirilecek kontrol mekanizmasıyla, etkin olarak sağlanması, balık türlerinin ve av araç gereçlerinin kullanımını içeren mesleki eğitim seminerlerinin verilmesi ve kendi ürünlerini pazarlayabilmelerine yönelik imkanlar sağlayacak teşvik ve desteklerle balıkçılık faaliyetlerinin artırılması mümkün olabilecektir.

Teşekkür: Bu çalışma Ordu Üniversitesi BAP birimi tarafından desteklenmiştir (B-1801 nolu proje).

\section{KAYNAKLAR}

Anonim, (2013). Yozgat il çevre durum raporu $\begin{gathered}\text { 2012. Alıntılanma } \\ \text { https://webdosya.csb.gov.tr/db/ced/editordosya/Yozgat_icdr2012.pdf (20.05.2019). Adresi: }\end{gathered}$
$\begin{gathered}\text { Anonim, (2018a). } \\ \text { https://www.enerjiatlasi.com/hidroelektrik/(20.05.2019) }\end{gathered}$


Anonim, (2018b). Kırşehir ili coğrafik yapısı. Kırşehir Valiliği, Alıntılanma Adresi: http://www.kirsehir.gov.tr/cografya (20.05.2019).

Anonim, (2018c). Nevşehir ili coğrafik yapısı. Nevşehir Valiliği, Alıntılanma Adresi: http://www.nevsehir.gov.tr/kurumlar/nevsehir.gov.tr/ilimizrehber/2018yeni/cografi.pdf (20.05.2019).

Anonim, (2018d). Kayseri ili coğrafik yapısı. Kayseri Valiliği, Alıntılanma Adresi: http://www.kayseri.gov.tr/daglar-ovalar-akarsular-ve-goller (20.05.2019).

Anonim, (2019). Tarımsal örgütlenme tablosu. Tarım ve Orman Bakanlı̆̆ı. Alıntılanma Adresi: http://www.tarimorman.gov.tr/TRGM/Link/33/Tarimsal-Orgutlenme-Tablosu (03.03.2019).

Bayhan, Y. K., Korkmaz, S., \& Olgunoğlu, M. P. (2014). Adıyaman ili balıkçılığının mevcut durumu ve sorunları. Yunus Araştırma Bülteni, 4, 37-46.

Canpolat, İ., Memişoğlu, E., Gürçay, S., Birici, N., \& Arısoy, G. (2015). Elaziğ ili su ürünleri kooperatiflerinin mevcut durumu. Yunus Araştırma Bülteni, 1, 11-21.

Celayir, H., Pala, M., \& Yüksel, F. (2006). Keban Baraj Gölü Balıkçılığı. I. Baliklandirma ve Rezervuar Yönetimi Sempozyumu 7-9 Şubat 2006 (s 259-268), Antalya.

Duman, E., \& Karadağ, Y. (2017). Keban Baraj Gölü Kemaliye Bölgesi’nde kullanılan av araçları. Ege Journal of Fisheries and Aquatic Sciences, 34(2), 195-201. DOI: 10.12714/egejfas.2017.34.2.11

Duman, E. (1998). Türkiye Balıkçılı̆̆ı. Yüksek Lisans Tezi, Fırat Üniversitesi, Fen Bilimleri Enstitüsü, Su Ürünleri Anabilim Dalı, Elazığ.

Karademir, M., \& Arat, M. E. (2014). Su ürünleri kooperatiflerinde karşılaşılan sorunlar ve çözüm önerileri: İstanbul ili örneği. Marmara Üniversitesi Öneri Dergisi, 11(41), 133-156.

Orsay, B., \& Duman, E. (2005). Kemaliye, Peri ve Göktepe bölgelerinde kullanılan balıkçlık av gücü ve çeşitli özelliklerin incelenmesi. Fırat Üniversitesi Fen ve Mühendislik Bilimleri Dergisi, 17(1), 121-129.

TÜİK, (2018). Su ürünleri istatistikleri. Balıkçılık ve Su Ürünleri Genel Müdürlüğü, Ankara.

Ural, M., \& Canpolat, İ. (2009). Doğu ve Güneydoğu Anadolu bölgelerindeki su ürünleri kooperatiflerinin yapısı ve av araçları ile balıkçı teknelerinin teknik özellikleri. Türk Bilim Araştırma Vakfi, 2(4), 372-384.

Uzmanoğlu, S., \& Soylu, M. (2012). Yeni Karpuzlu Baraj Gölü balıkçılarının sosyo-ekonomik yapısı. Ege Journal of Fisheries and Aquatic Sciences, 29(4), 175-179. DOI: 10.12714/egejfas.2013.29.4.05 